\title{
El pensamiento complejo de Mary Richmond: algo más que una ventana al pasado
}

\author{
The complex thought of Mary Richmond: something more \\ than a window on the past
}

\author{
Alfonsa RodRíGUEZ RodRíGUEZ \\ Teresa Zamanillo Peral \\ Escuela Universitaria de Trabajo Sociall Universidad Complutense de Madrid \\ mzamanillop@telefonica.net \\ alfrodri@trs.ucm.es
}

Recibido: 09/06/2011

Revisado: 24/06/2011

Aceptado: 28/06/2011

Disponible on line: 29/09/2011

\section{Resumen}

El propósito de este artículo es hacer una nueva lectura de las dos obras de Mary Richmond, Caso social individual y Diagnóstico social, a la luz de los nuevos modelos que intentan analizar la complejidad de la vida social. El pensamiento complejo que inauguró la autora, de una forma espontánea y empírica, es de tal riqueza que ha merecido este esfuerzo. Con este trabajo tratamos de transmitir a los lectores -profesores de escuelas, profesionales y alumnos- el deseo de leer a los clásicos, en este caso a ella, con una voluntad y atención puestas en el diálogo para descubrir aquello que dijo pero que hay que leerlo entre líneas; y de aquello que no dijo porque no podía decirlo, ya que no disponía de los elementos de análisis necesarios para poder transmitirlo. Mas, a pesar de las limitaciones del conocimiento propias de la época, Mary Richmond siempre ha de quedar en nuestro recuerdo, como profesionales de la relación de ayuda, con el agradecimiento que se merece toda persona que ha puesto su poder al servicio de los demás.

Palabras clave: complejidad, teoría de la acción, mapa conceptual, reflexividad, ética.

\begin{abstract}
The purpose of this article is to read anew the two works of Mary Richmond, What is Social Case Work? and Social Diagnosis, according to new patterns that seek to analyze the complexity of social life. The complex thought created by the author, in a spontaneous and empirical way, is so rich as to deserve this effort. With this work, we attempt to transmit to readers - professors, professionals and students- the desire to read the classical writers, most especially this author in this case, with a will-power and attention focused on the dialogue to discover what she said but which must be read between the lines and what she did not say, since she did not have the necessary elements of analysis available to transmit it. In spite of the limitations of the knowledge typical of that time, however, we must remember Mary Richmond forever, as professionals of the help relationship and with the gratitude due every person who has given his or her power to help others.
\end{abstract}

Keywords: complexity, Action theory, conceptual map, reflexivity, ethics.

Referencia normalizada: Zamanillo Peral, T. \& Rodríguez Rodríguez, A. (2011). «El pensamiento complejo de Mary Richmond: algo más que una ventana al pasado». Cuadernos de Trabajo Social, 24: 69-84.

Sumario: Introducción. 1. La mirada compleja: cómo superar la disyunción. 2. Algunas ideas guía: una estructura comprensible dentro de una maraña. 3. El mundo de los significados/mundo de las relaciones (mundo interno/realidad externa). 4. El observador y lo observado. Comprender la idea de co-participación. 5. La familia y la red social como sistemas significativos y ejes de la intervención. 6. Referencias bibliográficas. 


\section{Introducción}

No es la primera vez que las autoras que suscriben este texto reivindican el valor de la obra de Mary Richmond, porque releer a los clásicos es una tarea que, a nuestro parecer, hay que hacer con frecuencia. Obtenemos con ello rememorar el pensamiento que había sido ya germinado en su esencia, y reelaborarlo desde otras perspectivas que se esfuerzan por actualizar el conocimiento con nuevas aportaciones. Retornar a sus obras es reconocer los atributos del Trabajo Social, sus particularidades más prístinas; es distinguirla de todos los demás que la han secundado; es no dejarla caer en el olvido, «ese predador del tiempo» (Ricoeur, 2005); es reencontrarse con un pensamiento enriquecedor que puede devolver al Trabajo Social gran parte de su identidad construida y reconstruida constantemente con hilvanes muy largos, sensibles a cualquier tropiezo que rasgue sus vestiduras. Y es que, como cualquier otra disciplina que ha tenido sus maestros, Mary Richmond se puede inscribir, sin pretender compararlos, en el mismo rango que la obra de Sigmund Freud, o la de Gregory Bateson: en el primero, porque La interpretación de los sueños y Estudios sobre la histeria constituyó el hito o viraje en la psicología tradicional; y en el segundo -el modelo sistémico-porque el artículo «Doble vínculo y esquizofrenia» supuso el «hecho fundante» de una perspectiva acerca del hombre y de la patología mental. De ahí que Natalio Kisnerman destaque, en el prólogo al libro Caso Social Individual, que su obra tiene la valía de los clásicos, de los «adelantados»».

Nuestro propósito es hacer una relectura de los contenidos epistemológicos implícitos en la obra de Mary Richmond desde las perspectivas actuales que intentan analizar la complejidad. Pensamos que si se hace una lectura concienzuda de sus escritos, prestándoles el debido interés que merecen, se puede comprobar que en su pensamiento existe una determinada concepción de la realidad, que denominamos perspectiva teórica, a través de la cual se establecen los presupuestos en los que se fundamenta la acción. Su lectura supone, en buena medida, recrear el escenario para la elaboración de nuevas actitudes en el proceso de intervención, determinados estilos vinculares e instrumentos técnicos y metodoló- gicos; todo lo cual hoy se mantiene vigente, pese a que los factores organizativos, profesionales y de la población hayan cambiado. En su esencia, Mary Richmond nos remite a cuestiones fundamentales sobre el Trabajo Social, es decir, permite desarrollar proposiciones teórico-prácticas de amplio alcance. Además, y a nuestro juicio, lo que le hace merecedora de este esfuerzo de análisis que hacemos en estas páginas, es que se trata de una autora precursora del pensamiento complejo. Todo lo cual pone de manifiesto que no es casual que se la cite como antecedente de las nociones nucleares del modelo sistémico aplicado a contextos psicosociales.

En esta nueva lectura hemos agrupado algunos temas que son claves en el análisis de sus dos obras fundamentales: Diagnóstico Social y Trabajo Social individual. En el primer apartado analizamos las consecuencias epistemológicas que han derivado de una mirada dicotómica sobre la realidad, ora psicologista, ora sociologista; mirada que pone en oposición dos aspectos del mundo social que forman una unidad inseparable. En el segundo apartado se proponen algunas ideas que pueden servir como guía: fundamentalmente la práctica reflexiva. Es este aspecto tan olvidado en Trabajo Social, al haberse hecho una cierta desviación, en los últimos tiempos, de una vía muy tecnificada, el que queremos destacar de este apartado. Se trata de invitar a los trabajadores sociales a analizar las complejidades propias del contexto social específico que rodea las dificultades psicosociales en la vida de las personas; se trata de examinarlas como un proceso en el que es preciso entrelazar las realidades personales y las sociales. El tercer apartado está dedicado al examen de los significados, de los mundos: interno del profesional y externo de los sujetos y de su entorno. Para acercarse al mundo de los significados se necesita adentrarse en las creencias a partir de las cuales los sujetos actúan. Nos encontramos, pues, ante una cuestión técnica de primer orden, que implica la autoobservación del profesional y la observación de la realidad externa. En el cuarto apartado se aborda la complejidad del encuentro profesional, la relación entre el observador y lo observado, con objeto de comprender la necesidad de la co-participación en los planes del 
sujeto o de la familia. Es la relación significativa y transparente y la vinculación que se establece entre el profesional y la familia lo que da sentido a la intervención. En el quinto epígrafe trabajamos los aspectos relacionados con la red social de los individuos y la importancia de la misma para el restablecimiento del problema. Por último, nos ocupamos de la dimensión ético-política del pensamiento de Mary Richmond.

\section{La mirada compleja: cómo superar la disyunción}

Recordar a Mary Richmond no supone un acto de nostalgia; más al contrario: rememorar el pasado nos va a permitir acercarnos a las más interesantes e innovadoras propuestas actuales que están en la línea de los enfoques teórico-prácticos que deberían iluminar las prácticas de los trabajadores sociales hoy en día. Y es que en esta autora el «mapa ${ }^{1} »$ no estuviera trazado como tal, pero en el mapa del territorio que esbozó encontramos elementos que posteriormente fueron conceptualizados por diferentes paradigmas innovadores por demás. $\mathrm{Su}$ «ideario» lo podríamos situar en teorías de tercer nivel: es el nivel de la acción, de la intervención, el nivel operativo; ahí situamos el case work que es Trabajo Social con individuos y familias.

Algunos puntos del mapa que se propuso trazar constituyen, desde nuestro punto de vista, lo «propio» de la mirada del Trabajo Social; «mirada» o lentes que sostienen, por un lado, un tipo de construcción del objeto (epistemología) y una definición de quiénes somos; es decir, determinada epistemología y ontología, en expresión de Bateson (1980). Nos referimos, entre otras cuestiones, a la definición del campo en el Trabajo Social: el individuo en su situación.

El título del presente epígrafe alude a la «ruptura de la disyunción» porque en la historia del Trabajo Social, como se ha dicho, ha imperado el modo de «pensamiento disyuntivo o el dualismo peyorativo» (Auerswald, 1995, p. 26), según el cual el universo está dividido en partes contrapuestas. Este dualismo afecta al Trabajo Social en la for- mación de dos corrientes contrapuestas, que han existido desde sus inicios: por un lado, el interés en la experiencia subjetiva the individual and neglect of the environment and social reform, el individuo y el descuido del medio ambiente y la reforma social; y, por el otro, el acento en la necesidad de transformar el medio social. ¿Corresponde a la realidad esta mirada? ¿O más bien se puede afirmar que solo existe el mundo social, aun cuando nos acerquemos a él de manera diferente? Las consecuencias de dicha disyunción han sido empobrecedoras para el Trabajo Social, habiendo dado lugar a dos mundos de lenguaje y de sentido, a nuestro hacer y nuestro ser, en ocasiones, dicotómico y simplificador. Así, desde la primera perspectiva hoy se confunde o se identifica al Trabajo Social con una actividad de índole tecnocrática e instrumental, dedicada a solucionar los problemas individuales; $y$, por el contrario, a esta manera de concebir la profesión se enfrentan aquellos que abogan por el cambio social, segunda de las disyuntivas.

¿Qué implica dicha dicotomía? Por una parte, individualización del problema, culpabilización de la víctima, protocolos estandarizados que renuncian a un trabajo de relación y reflexión; y, por la otra, una segunda posición que pone el énfasis en el cambio social, abogando por políticas emancipadoras. Muchas veces estas dos miradas defienden mundos separados. Cuando en realidad, por ejemplo, un trabajo de intervención familiar o grupal «terapéutico» [en el sentido que Luigi Cancrini (1991) le da a este término de promover el cambio], no ha de implicar una «desideologización», una ausencia de compromiso, una mirada en túnel al interior de la vida de las personas, una descontextualización del sufrimiento, de su identidad. Porque, desde nuestro punto de vista, la cuestión primordial es cómo conceptualizamosabordamos la situación. Para Fernando Vidal (2010), respecto a la exclusión, la «radical personalización» no es subjetivismo y es necesario poner de manifiesto que «los excluidos tienen rostro singular y que su sufrimiento no es acumulable ni reduci-

1 Para Korzybski, el mapa « no es el territorio que representa, pero si es correcto tiene una estructura similar a la del territorio, lo que justifica su utilidad» (citado en Selvini, 1990, p. 356). 
ble a sufrimiento colectivo» (p. 126). Y es que entender qué consecuencias tiene para el grupo, el sujeto o la familia, determinado tipo de situación no implica establecer una relación de causa-efecto lineal. Veámoslo muy brevemente con una realidad que nos es familiar a los profesionales de la intervención social hoy: la situación de los inmigrantes.

Las familias inmigrantes acuden a los diferentes servicios socioeducativos con situaciones diversas (véase dificultades de adaptación de los niños al ámbito escolar, violencia de género, conflictos relacionales tras el reagrupamiento familiar, y un largo etcétera). La cuestión clave es cómo «armamos» la definición de la situación, porque es evidente que toda práctica incorpora una definición del problema. Si lo hacemos sin tomar en consideración la situación de stress y crisis transicional por la que está pasando la familia, se están produciendo varios errores, a saber: epistemológico ya que los fenómenos sólo son comprensibles en tanto que el marco -contexto- de observación es suficientemente amplio (Watzlawick, 1983); y, en segundo lugar, si conceptualizamos como un problema individual (familiar) lo que es un problema que se asienta en situaciones de desigualdad, explotación, etcétera, cometemos un error ético. En definitiva, es necesario tomar en consideración los dilemas en los que están atrapadas estas familias, que no son exclusivamente propios -solamente lo es su experiencia- y que sólo adquieren sentido si tomamos en cuenta que forman parte de problemas sociales más amplios (pero que tienen un potente efecto en la experiencia individual). Así, apoyar a estos padres de los menores inmigrantes no puede llevar a pensar que las dificultades de aquéllos son la causa de la situación.

Sin embargo, en la lectura que proponemos de Mary Richmond no encontramos dicha dicotomía cuando señala que el Trabajo Social «posee su propio campo de acción, esto es, el desarrollo de la personalidad por la adaptación consciente y comprensiva de las relaciones sociales. Así, no se pueden descuidar ni las anomalías del sujeto ni las del medio». La singularidad reside en:

Alcanzar al individuo por intermedio de su ambiente (...) Mientras los seres humanos sigan siendo humanos y su medio siga siendo el mundo, no se podrá imaginar un estado de cosas en el que ellos mismos y el medio en que viven dejen de necesitar adaptaciones y readaptaciones particulares (Richmond, 2005, p. 67).

Tenemos necesidad de desembarazarnos de los últimos vestigios de esta concepción que nos obsesiona todavía y que hace rendir la inteligencia del hombre en alguna parte de su cabeza o en un lugar cualquiera del espacio. La constitución mental del hombre está formada por la suma de sus clones naturales y de las experiencias y las relaciones sociales que ha tenido hasta ese momento (p. 87).

¿Qué implicaciones tiene esta afirmación desde una perspectiva sistémica ${ }^{2}$ acerca de la naturaleza del otro? Tomamos un artículo reciente de Carlos Sluzki (2007) titulado Interfaces toward a new generation of systemic models in family research and practice, en el que plantea la necesidad de que el modelo sistémico siga profundizando la recursividad de los diferentes dominios de la realidad, sin exclusión de ninguna:

Los procesos mentales, el estrato neurobiológico, y el mundo social/relacional funcionan como un sistema, y como tal, recíprocamente se influyen mutuamente. (...) Cabe señalar que «lo social/mundo relacional» es inclusivo de varias capas sistémicamente relacionadas: la familia, las redes sociales personales, la comunidad, el entorno socioeconómico, el nicho ecológico, y así sucesivamente (p. 174).

Para el autor, podríamos añadir: el mundo social abarca dos niveles, el «micro-social» de la familia y de la red relacional inmediata y el nivel «macro-social» del mundo en donde aquella está inmersa, lo que incluye las variables socioeconómicas, movilidad, variables culturales y prácticas, etnia y otros rasgos de inclusión/exclusión social que im-

2 En la actualidad es preciso referirnos más que a «perspectiva sistémica» a «movimiento sistémico» en el que tienen cabida diferentes «voces». Dichas «voces» como acertadamente señala L. Hoffman $(2001$, p. 21$)$ son «a veces narrativas, a veces posmodernas, a veces postestructuralistas». 
pactan los recursos y la resiliencia individual y familiar. Para Sluzki, el mundo micro-social de la familia es:

Una estructura intermedia, muy sensible a los cambios en el nivel neurobiológico y mental de los procesos, y que les afectan fácilmente; también es igualmente sensible a los rasgos y los cambios en el reino macro-social. Al mismo tiempo, la familia y las redes sociales personales tienden a amortiguar los cambios en cualquiera de los niveles de los procesos (pp. 175-176).

Desde el punto de vista de la intervención es preciso, pues, no perder de vista «las interfaces como un lugar central de sus prácticas, porque esas interfaces son el territorio de una buena parte de la fuente de dolor y sufrimiento, y de la evaluación y cambio». Es ineludible, por tanto, analizar e iluminar esas interfaces, sus componentes, sus influencias, $\mathrm{y}$ «sus potenciales desajustes, desestabilizando cualquier narrativa tradicional de dominancia de un nivel de análisis sobre los otros»». En definitiva, estamos preservando que el núcleo de Trabajo Social, es decir, de su construcción del objeto, es la comprensión del individuo y la comprensión de su medio, así como la acción directa e indirecta del o de la trabajadora social sobre el individuo y sobre el medio en el que habita, entendiendo que este habitar se desarrolla en el espacio en el que se mueve el sujeto y despliega su conducta social ${ }^{3}$.

Que los trabajadores sociales no hayamos encontrado dicha articulación no ha de hacernos decaer; de hecho, en otros campos tampoco lo han logrado, sobre todo si tenemos en cuenta que las «teoría de la acción» sitúan a estas disciplinas, la nuestra, en los terrenos pantanosos de los que habla Donald Schön (1998). Estos profesionales -dice Schön- manifiestan un «sentimientos de inferioridad» en relación a aquellos que lejos del pantano, en las zonas altas, solo quieren construcciones alrededor del uso de modelos formales analíticos. Porque, pensamos, además, que hemos de nutrirnos de aquellos que han podido y pueden contribuir al análisis y la reflexión en estos campos, aquellos que han roto la disyuntiva. Por ejemplo, el concepto de habitus de Bourdieu (2007) es de una potencia analítica que lo hace ineludible porque nos permite «superar dilemas dualistas» y a «interpretar mejor las prácticas de los agentes sociales que pueden parecernos incomprensibles, paradójicas o irracionales»; nos posibilita, por tanto, «hacer diagnósticos más precisos sobre las respuestas diferenciadas ante situaciones objetivamente similares, peor percibidas $y$ afrontadas de modos diferentes en función de experiencias anteriores profundamente arraigadas: o a evitar culpabilizar a las víctimas de situaciones donde se ven atrapadas»» (Fernández, 2003, p. 26). Otra perspectiva enormemente enriquecedora es la que se propone articular las ideas del construccionismo social y las prácticas o enfoques narrativos; o también aquella que con nuevos desarrollos críticos integra la teoría de Freire con nociones de terapia familiar narrativa. De esta perspectiva se dará cuenta en el último apartado.

En definitiva, proponemos enfoques que investiguen nuevas formas de analizar la realidad y consigan dar sentido a las grandes macroestructuras (comprender al otro tomando en consideración el género, la cultura, la etnia, la clase social, etcétera). Se trata de acercarse al otro reconociendo el enorme efecto que tienen todos estos factores en su experiencia personal. Marcelo Pakman (2006) al referirse al abordaje de las familias multiproblemáticas en salud mental, señala que:

Tenemos suficiente investigación como para apoyar el concepto de que muchas situaciones vitales (abuso físico o sexual, exposición a violencia domestica, abandono precoz, etc.) son patogénicas en sí mismas y deben ser evitadas en cualquier sociedad que se preocupe por el futuro potencial de sus miembros (p. 4).

Consideramos necesario, pues, trasladar estas observaciones a nuestro campo del Trabajo Social para ayudarnos a reflexionar so-

${ }^{3}$ Se utiliza este término en el sentido que le da Simmel: el espacio es para el filósofo «no sólo un lugar físico, sino una construcción social resultado del entramado de las relaciones individuo/grupo. El espacio tiene (...) una historia que se modifica social, económica, política y simbólicamente». Es la acción recíproca la que hace posible la relación entre los individuos (Olvera Serrano, M. 2007, p. 247). 
bre lo que el autor denomina micropolítica. En estos programas se subraya el componente sistémico no como:

Un grupo específico de técnicas psicoterapéuticas, sino como un espíritu y una metodología que cuestiona el concepto mismo de que los complejos problemas que enfrentan las familias multiproblemáticas sean problemas exclusivamente psicológicos y usa, en cambio, múltiples lentes para enfocarlos. Micropolítica significa también operar llevados por nuestra voluntad profesional y la buena intención de profesionales comprometidos en favorecer a las poblaciones carenciadas sin sacrificar la voluntad de los sujetos de la intervención. Un delicado equilibrio pendula entre la conciencia de los mecanismos triviales en juego en la vida de las personas acerca de los cuales queremos que ellas estén informadas (del mismo modo que saber acerca de y recibir una vacuna para una enfermedad prevenible es un derecho humano y algo bioéticamente correcto de hacer) y la necesidad de reconocer el límite dado por el derecho de las personas a decidir por si mismas (pp. 5-6).

Siguiendo con la idea que estamos desarrollando en este apartado -la complejidad-, la noción de causalidad múltiple encuentra un espacio en las reflexiones de Mary Richmond, cuando plantea la necesidad de evitar la simplificación en el diagnóstico (2005, p. 417) y, por ende, en la intervención. Aun cuando es consciente de las dificultades que implica un análisis integral de las situaciones, advierte que es necesario seguir reflexionando, ya no tanto en recoger un material completo de fortalezas y debilidades, de innumerables variables, sino en la articulación $\mathrm{y}$ valoración de todo ello como un todo ( $\mathrm{p}$. 406). Así, indica que «la acción recíproca de las causas y los efectos, tan característicos de los fenómenos sociales» (1982, p. 93) es imprescindible, mas «el intento de asimilación global de estos aspectos es un asunto complicado (...). Viudedad, abandono, ilegitimidad, no son más que hechos sociales aislados carentes de significado hasta que se conoce el contexto que los rodea en cada caso» (2005, p. 419). Por ello, plantea la necesidad de trascender las variables, el sumatorio de las mismas (relatos individuales, familiares, etcétera), ya que la conexión de unos datos con otros es lo que les da significado. Porque sólo en su «conjunto indican la naturaleza de las dificultades sociales de un determinado cliente» (p. 25). Así pues, a pesar de que Mary Richmond nos instaba a mirar la complejidad, y también en las declaraciones formales se exhorta a la profesión y la disciplina a centrarse en las interacciones entre sistemas, la pregunta de hoy es ¿por qué se sigue formando a los trabajadores sociales a hacer diagnósticos fragmentados en los que se señalan los problemas de vivienda, salud, educación, etc. como factores aislados que carecen de perspectiva o mapa que les dé sentido? Nos encontramos no sólo ante una cuestión de metodología sino también de ética, como se ha apuntado más arriba y se refrendará en el último apartado 4 .

\section{Algunas ideas guía: una estructura com- prensible dentro de una maraña}

¿Qué logró Mary Richmond? Convertir una situación problemática en un problema bien formulado; dar nombre y enmarcar: «cuando se discierne una estructura comprensible dentro de una maraña»; el valor de empezar a formular objetivos; y respecto al conocimiento que procede del sentido común, o conocimiento hoy llamado tácito, la autora puede ser una fuente válida de conocimientos; incluso, a pesar de que no formalizó esa perspectiva o mapa teórico que estamos proponiendo en este artículo, ya que a veces sus afirmaciones parecen tan de sentido común que se considera muy difícil hallar dichos fundamentos. Pero el esfuerzo de este trabajo - mirar con nuevas herramientas viejos enfoques, el del case work en este caso- nos hace confiar en que en el curso de este análisis queden demostrados los fundamentos conceptuales de la autora. Y es que las dificultades para formali-

4 Para acercarse a los aspectos éticos implicados en el proceso metodológico, se recomienda leer «Apuntes para una valoración diagnóstica», Rodríguez, A. y Zamanillo T. (1992) Revista de Treball Social ,127, 121-139. En este artículo se pone de manifiesto la relación entre ética, teoría y técnica a través de dos miradas muy diferentes en un caso de intervención social con un menor. 
zar el conocimiento en estos campos, ya lo hemos dicho, son múltiples. He aquí el gran problema: hasta ahora, en las teorías de tercer nivel no se ha formalizado el conocimiento en mapas. Es a partir de los desarrollos que conocemos en el enfoque sistémico, en materia de familia, cuando podemos hablar de teorías de la intervención que orientan a ésta para acompañar a las personas a resolver sus dificultades.

Pero para sustentar las observaciones de Schön y comprender los esfuerzos teóricos que hizo Mary Richmond, volvamos a ella, señalando sus hallazgos: afirma que entre la descripción de lo que hacen los trabajadores sociales, los elementos que se ponen en juego y las concepciones teóricas ha de haber un proceso constante reflexión-acción-reflexión; se hace obligado el diálogo entre la teoría y la práctica. Así pues, lo que la autora denomina humildemente «diversas operaciones o métodos» esconde un «principio organizativo», es decir, constituyen una «epistemología inconsciente», en palabras de H. Mouro (2001, p. $25)$. Así se logra convertir una situación problemática en un problema bien formulado, dar nombre y enmarcar. Para Mary Richmond el diagnóstico social desafía el trato estadístico y el conocimiento intelectual, si bien este último debe ir acompañado de la valoración del profesional (siendo consciente de sus prenociones). Y añade que cuanto más claro tenga el «entrevistador los factores que debe conocer, más fácilmente podrá evitar el tic de examinador burocrático». Todo ello tomando en cuenta el discurso, el significado que los sujetos dan a su realidad.

¿Qué conocimiento común podrían asumir los trabajadores sociales? La autora rechaza, como hemos visto, los saberes prácticos como único sustento; además, añade, hay que considerar «el componente personal del profesional», ya que, el diagnóstico que no tome en consideración el conocimiento estará abocado al fracaso: «Su actitud ante las discapacidades $^{5}$ sociales y su tratamiento, junto con su instinto innato para evaluar los hechos y valores de la naturaleza humana, son parte integral de su filosofía social. Cada una de las etapas que componen los procesos» (Richmond, 2005, p. 111).

Detrás de dichas formulaciones está la propuesta de práctica reflexiva; la cual permite conceptualizar o entender la intervención sociofamiliar y la formación como prácticas contrapuestas a concepciones técnico-racionales, a las cuales critica con tanta elocuencia Schön. Práctica reflexiva que supone la concepción de que el conocimiento nunca es completo, puesto que constantemente está siendo modificado a través de la práctica y la reflexión. Son las aguas pantanosas a las que aludíamos, marco inestable por demás, propio de nuestra práctica, que exige una perspectiva pluridimensional por cuanto aquélla lleva implícitas dimensiones problemáticas per se: determinado modelo de sociedad, diferentes enfoques teóricos, variados y complejos contextos organizativos e institucionales, además de ciertos estilos relacionales.

Todo ello hace imprescindible poner en el centro del proceso de intervención el examen de las complejidades propias del contexto social específico que rodea a las dificultades psicosociales en la vida de las personas en un proceso en el que es preciso entrelazar las realidades personales y sociales, a fin de promover una conciencia crítica acerca de las mismas. Lo apuntado es constitutivo y constrictor de nuestra mirada, de nuestras lentes, crea realidad, hace que las cosas «sean» y se puedan o no transformar. En nuestro ámbito una concepción técnico-racional, cual cirujano que tras perfeccionar su procedimiento técnico opera con independencia de las cuestiones contextuales (Pakman, 1999), es inviable. Porque la intervención ha de estar enraizada en cada situación, evitando que no adquiera formas ciegamente ideológicas o que seamos meros ejecutores del control social tecnoburocrático.

5 No vamos a entrar aquí a justificar el término «discapacidad» por entender que tiene un sentido y una razón de ser en la época en que fue formulado por M. Richmond, mas si queremos hacer notar que dicho término fue traducido, en la primera traducción parcial de la obra Social Diagnosis (Textos seleccionados, en Talasa), por «habilidades sociales». Dicho término responde, desde nuestro punto de vista, a una concepción del sujeto-objeto de intervención nada carente de connotaciones valorativas y conceptuales. 


\section{El mundo de los significados/mundo de las relaciones (mundo interno realidad ex- terna)}

Observamos que la atención que Mary Richmond presta al mundo de los significados, necesita conocer el «modelo» o creencias a partir de las cuales los sujetos actúan, de lo que se deduce una cuestión técnica de primer orden: la autoobservación y la observación. La primera es una condición ineludible para evaluar el ejercicio profesional. Se trata, entre otras cosas de no repetir los errores producidos por las creencias o prenociones que envuelven irremediablemente el encuentro con el otro, si el profesional no se escucha a sí mismo o no presta la atención debida a su mundo interno; se trata de no hacer proyecciones masivas de nuestro mundo interno. $Y$ al hablar de la necesidad de la autoobservación de la realidad interna, no podemos dejar fuera a Harry Aponte (1985) al referirse al componente personal. Así, este autor señala que es preciso articular el aprendizaje de estrategias conceptuales y operativas, con una cierta revisión crítica de los propios aspectos del sí mismo. En nuestro ámbito de trabajo es necesario, dice Aponte (p. 89), el aprendizaje de cuatro tipos de habilidades: externas (técnicas), interiores (integración personal de la propia experiencia), teóricas, es decir, modelos y marcos de referencia contextuales necesarios para identificar y guiar el proceso de intervención; y, la capacidad de colaboración. Asimismo, este tipo de cuestiones son fundamentales en la formación de los alumnos con el fin de flexibilizar y enriquecer la cantidad y la calidad de las respuestas que en el futuro pongan en marcha en su ejercicio profesional y en la colaboración con los demás.

Y la segunda cuestión técnica, aunque parezca obvio lo que vamos a afirmar a continuación, no está de más recordarlo: la observación de la heterogeneidad del universo en el que vivimos ha de ayudarnos a representarnos ese mundo como un multiverso (Maturana), reconociendo la procedencia de cada uno de nosotros, recordando frecuentemente que procedemos de mundos diferentes, mundos que han constituido nuestra personalidad de manera muy disímil a la de los otros, no solo nuestros compañe- ros, sino las personas y familias con las que participamos en su proceso de reconstrucción. A este respecto así se expresa Mary Richmond:

No hay duda de que los trabajadores sociales que se ocupan de casos individuales tienen también su propia disposición de espíritu basada principalmente en la naturaleza del hogar en el cual han crecido, pero los que toman más a pecho su tema y su tarea aprenden a liberarse de sus inclinaciones, o por lo menos a contar con ellas en los juicios que se forman (1982, p. 119).

Es peligrosamente fácil para los trabajadores sociales asumir un papel, que al fin es egoísta y autocrático, y ponerse en primer plano por acciones que, desinteresadas en apariencia, obligan a sus clientes a limitarse a la actuación pasiva, obligada. (...) proporcionarle un estímulo apropiado (apropiado para ella) que le impulse a desempeñar su papel, es ayudar adecuadamente no solamente en nuestra concepción de las cosas, sino en la de ella (p. 114).

Con respecto a la realidad externa también habrá que renunciar a datos objetivos que nos faciliten otras fuentes de información si ello implica que perdamos de vista «las verdades íntimas de la personalidad que son todavía más importantes»: las esperanzas, los temores, los planes y la historia anterior. Así, analiza las dificultades en la crianza de de una madre en virtud del modelo interno vincular de la misma: el modelo autoritario, maltratador que sufrió la madre le lleva a ser muy permisiva con sus hijos (p. 53). En definitiva, las familias tienen sus propios planes y sus propios ideales, su propia construcción del mundo, lo que hay que tener en cuenta porque tiene efectos pragmáticos muy potentes en sus vidas y en sus relaciones.

De esta forma, los propios planes, las expectativas, y la actitud vital del cliente son más importantes que cualquier otro elemento de la información: las creencias familiares, el modelo a través del cual se construyen los significados y se actúa. Y es que, recordemos, no es posible separar las partes del todo para conocerlas y luego restituirlas al todo, dice Mary Richmond. Lo analítico que separa no da cuenta del «todo». Así, aunque aborda la totalidad de manera muy primaria logra acer- 
carnos a esa concepción compleja que venimos analizando: sentimos

La necesidad de tener el punto de vista de ella», pero se «necesita convocar el punto de vista de él (...). Con la primera entrevista exhaustiva con la familia se evita despilfarro de tiempo y energía (...). Es preciso investigar las relaciones sociales del cliente (...) la actitud de la familia hacía él, así como su actitud hacía ellos.

Y además,

El hecho de las relaciones sociales sean dinámicas, sugiere la idea de que la fase que sigue al desarrollo, consiste en poner frente a frente el cliente y a las personas, las cuales mantienen relaciones sociales, o en hacerle tomar contacto por lo menos con alguna de estas personas. Podemos entonces ver esas relaciones mientras actúan en vez delimitarnos en obtener una descripción de segunda mano (p. 92).

Es preciso repetirlo: necesitamos ver interactuar al sistema para comprender su funcionamiento. La analogía con la mirada diagnóstica sobre la estructura familiar que desarrolla Salvador Minuchin (1977) -de lo que daremos cuenta en el siguiente apartado-, se plantea en estas reflexiones en la afirmación de que sólo se puede conceptuar cuando se observa a la familia en interacción.

\section{El observador y lo observado. Compren- der la idea de co-participación}

Para Lynn Hoffman (1996) una nueva o no tan nueva perspectiva epistemológica ha de incorporar nociones acerca de los «sistemas observantes»: aquella que sostiene que el observador es agente constructor de la realidad que se está observando y, por lo tanto, está implicado en ella de tal forma que su influencia en lo observado (cliente, familia, grupo, comunidad) es ineludible. Evidentemente dicha concepción es familiar en ciencias sociales, mas en el ámbito de la intervención psicosocial constituye para muchos profesionales un desafío, por cuanto lleva a cuestionarnos aspectos fundamentales de nuestras concepciones teórico-prácticas: una relación de colaboración no jerárquica entre las partes (o al menos tener conciencia de los riesgos que conlleva la relación en estos términos); situar la intervención teniendo en cuenta sus límites; limitaciones en nuestros instrumentos técnicos; apertura a la transparencia; visión optimista; influencia de nuestras ideas preconcebidas en el sistema observado, etcétera. Evidentemente no encontramos en la autora las formulaciones que apenas hemos enunciado, sin embargo, sí están o se intuyen algunas preocupaciones al respecto. Por ejemplo, en Mary Richmond se puede inferir que concibe el encuentro profesional como un nuevo sistema -formado por el trabajador social y la familia-, que va tener sus propias reglas y no va a poder ser gobernado de manera unilateral. De ahí que los «consejos» no sirvan:

La sensación de frustración en las personas con las que trabajamos no cede frente a consejos generales, vagos y optimistas. (...) aprender el arte de descubrir lo que interesa principalmente al sujeto y saber aprovechar las inclinaciones de éste para reanudar lazos rotos o para darle lo que le falta, una finalidad en la existencia (p. 89).

Es consciente de que, más allá de la realidad objetiva del otro, está el mundo de los significados que organiza la experiencia interna y que «habla» en un lenguaje oculto, pero contundente, como se puede ver en sus relatos de historias de maltrato transgeneracionales o en los movimientos ambivalentes y contradictorios de los miembros de la familia, a los que hay que darles un sentido. En este aspecto reflexiona lo siguiente:

Cierta noción sobre sus actitudes frente a la vida. (...) Como la señora evita el modelo de maltrato y autoritario a ella y es muy permisiva con sus hijos. Las familias tienen sus propios planes y sus propios ideales, y los tienen mucho más claros de lo que la trabajadora social se imagina. Conviene entender esto desde el principio y tenerlo siempre muy en cuenta. De otra forma, nuestros planes se verán irremediablemente abocados al fracaso. (...) Las «creencias familiares», es decir, como los otros reformulan la conducta del señor es una fuente de resistencias (p. 53).

De esta forma, los propios planes, las expectativas y la actitud vital del cliente son más importantes que cualquier otro elemento de la información: las creencias familiares, el modelo a través del cual se construyen los significados y se actúa. Y es que, 
recordemos, no es posible separar las partes del todo para conocerlas y luego restituirlas al todo, dice Mary Richmond. Lo analítico, que separa no da cuenta del «todo». Así, aunque aborda la totalidad de manera muy primaria, logra acercarnos a esa concepción compleja que venimos analizando: sentimos la necesidad de tener el punto de vista de ella, pero se

Necesita convocar el punto de vista de él (...). Con la primera entrevista exhaustiva con la familia se evita despilfarro de tiempo y energía (...). Es preciso investigar las relaciones sociales del cliente (...) la actitud de la familia hacía él, así como su actitud hacía ellos (2005, p. 113).

Y además, sostiene la idea nuclear en intervención familiar, desde una perspectiva sistémica, de que sólo se puede conocer la dinámica de la familia viéndola «danzar» (Minuchin y Fichman, 1984), es decir, necesitamos ver interactuar al sistema para comprender su funcionamiento.

El establecimiento de un buen entendimiento unido a actuaciones concretas. Frente a clientes que traen su «historia preparada», pese a lo cual es parte de la historia aunque no sea más que «un fragmento secundario» está basada en una historia real y posee parte de autenticidad. El trabajador social habrá de explicar siempre el por qué de sus decisiones (1982, p. 33).

$\mathrm{Y}$ en otro lugar prosigue afirmando la necesidad de la alianza de trabajo:

Que no se fija en los síntomas más evidentes, sino que nuestra intuición sorprendente acerca de aspectos cuya relación con el problema del paciente desconoce (...) una vez establecida una sólida relación personal con visos de continuidad (2005, p. 193).

En definitiva, podríamos seguir recogiendo numerosas máximas, actuales por demás, como cuando alude a la necesidad de cooperación y dice que: «Encarrilar una conversación no implica que tenga que ser forzosamente cuestionada». Este aspecto queda patente en las obras que analizamos:

Hablemos para analizar el tema juntos ¿Cómo empezó todo y qué creen que va a pasar? Estoy a su disposición. ¿Se pararon a reflexio- nar detenidamente el asunto? (...) la respuesta es casi siempre gratificante». Por ejemplo: "podría hacer con su vida lo que desee ¿qué?» (p. 118).

Por otro lado, como señalamos antes, cuando el consejo con la familia no promueve cambios hay que trascender lo educativo. Traspasar la máxima que dice que «la información promueve el cambio»y exige analizar el modelo de creencias de la familia. Para conseguir su transformación, el análisis de dicho modelo tendrá que hacerse por medio del diálogo; se trata de una conversación extraordinaria que se realiza a través de preguntas informadas que arrojan luz a la comprensión de la situación (H. Anderson y H. Goolishian, 1996). En esta línea podemos deducir principios o técnicas de un enfoque narrativo, en el que por medio del relato del otro se pueden buscar los acontecimientos extraordinarios que eviten las descripciones saturadas de problemas (M. White y D. Epston, 1993), así plantea que rememorar los mejores momentos alivia la angustia y nos proporciona, «buscar una base más amplia de conocimiento, orientando al cliente hacia sus esperanzas y posibilidades futuras, y hacia sus relaciones pasadas más felices» (p. 111).

En sus obras encontramos también operaciones de autorreflexividad, cuando dice que el profesional ha de reservar una parte de su tiempo a tratar de analizar críticamente su propio trabajo desde una perspectiva objetiva. ¿Cómo? Buscando un tercero que analice la relación entre el observador y lo observado, recurriendo a la supervisión o autosupervisión; en el cuestionario de los supervisores se encuentran preguntas en torno a la relación del trabajador social de casos con el cliente, con su familia y en general. En este sentido plantea la necesidad de comprender, si el material del que disponemos puede revelar contradicciones ocultas en los datos. Por su parte, si acudimos al presente, como venimos invitando al lector en todo momento, Luigi Cancrini (1991) plantea que la falta de comprensión o contradicciones encontradas en la comprensión de las situaciones que abordamos los profesionales, se debe, las más de las veces, a falta de información por nuestra par- 
te y nunca al azar. El sistema asistencial ha de tener algunas características, nos dice Mary Richmond porque:

Es peligrosamente fácil para los trabajadores sociales asumir un papel, que al fin es egoísta y autocrático, y ponerse en primer plano por acciones que, desinteresadas en apariencia, obligan a su cliente a limitarse a la actuación pasiva, obligada (1982, p. 114).

En estas palabras se observa cómo la autora intuye el concepto de resistencias al cambio del cliente como una "sublevación» del sujeto. Resalta también la necesidad de una relación de paridad con el cliente al mostrar su empatía:

Puede sucederle a cada uno de nosotros -nos ha sucedido a todos más de una vez-que nos encontrarnos inadaptados a nuestro ambiente, a causa de nuestra incapacidad para elevarnos a la altura de las circunstancias (p. 89).

Por otra parte, si centramos la atención en un aspecto clave de la intervención, vemos que la evaluación y la intervención constituyen un continuum, en la medida en que seleccionamos unos datos de la realidad y desestimamos otros. Según expresa Stefano Cirillo (1991), ya constituye una información-transformación para el sistema. De la misma forma, para la autora: «No es ningún disparate afirmar que la investigación continúa a medida que lo hace el tratamiento». Esta concepción nos lleva a considerar su oposición a los diagnósticos fotográficos, fijos; así introduce la idea de proceso destacando cómo la acción del propio trabajador social y los recursos que moviliza cambian el objeto observado. Por ello, el propio diagnóstico ha de: «buscar discretamente las causas y modificar las ocasiones de estímulo que alienten a fin de descubrir en qué medida cada uno de los miembros de la familia reaccionaría bajo la influencia de condiciones físicas mejores y recursos más regulares (p. 51).

Los diagnósticos fotográficos, o dicho de modo más común, el etiquetaje, nos da una representación carente de voces que cuenten una historia de acercamientos y rechazos, de gestos y acciones que dicen algo a alguien; constituye un marco, en definitiva, que res- tringe la observación a los individuos y deja fuera a las instituciones implicadas, cuando en realidad todo ello constituye parte de la historia. Por último, destaca el análisis de las posibilidades y las restricciones que provocan la naturaleza del servicio, el origen de la asistencia, el lugar de la entrevista, y el historial disponible.

\section{La familia y la red social como sistemas significativos y ejes de la intervención}

El trabajo de casos desde sus inicios siempre fue Trabajo Social con familias. Vemos cómo Mary Richmond toma en consideración los cambios que se estaban produciendo en los modelos familiares, producto de la urbanización creciente y de la inmigración en Estados Unidos, y cómo en el trabajo por el bienestar de un individuo aislado, aun cuando fuesen buenos los resultados, éstos se neutralizarían si se ha ignorado la historia y el trabajo con su familia.

Descubriríamos que los buenos resultados del tratamiento individual se evaporan, a menudo, porque el trabajador social ha pasado por alto la historia familiar del cliente. De repente, y generalmente demasiado tarde, el profesional social se da cuenta de ello, cuando salen a la luz ciertas tendencias que han estado durante mucho tiempo ocultas (2005, pp. 139-140).

En su concepción de la familia, y en el análisis concreto que realiza en los casos examinados, plantea una perspectiva transgeneracional (Bowen, 1991; Boszormenyi-Nagy y Framo, 1996; Stierlin, 1996) que se observa cuando manifiesta que determinados padres evitan determinados estilos vinculares y de crianza con sus hijos como una forma de evitar, a veces repetir, el modelo que arrastran de los propios.

La importancia del vínculo la plantea a caballo entre la perspectiva psicoanalítica, no freudiana, que tiene en cuenta la intersubjetividad y la sistémica. Vemos esto en su perspicacia al señalar que dichos vínculos son «primigenios» aunque estén cargados de ambivalencias: «Ella parecía amar a sus hijas pero las descuidaba». Para Zazzo (1977) la vinculación es una necesidad primaria, lo que constituye un hito en Psicología; no la impor- 
tancia de la vinculación como fenómeno observable que todos conocemos, sino como efecto de un impulso primario. Considerar la vinculación como necesidad primaria, al igual que la alimentación o la autoconservación no sólo cuestiona y contrasta con la teoría tradicional de la libido sino, y es lo más importante para nosotras ya que resalta la vinculación como algo de un orden superior, primario, tan vital o más que el alimento para el bebé. Los etólogos ya lo advierten: la apertura hacia el otro, la dimensión social está enraizada biológicamente. Hacemos las referencias anteriores aun sabiendo, con el autor, que el hiato entre el mundo del comportamiento animal y el humano es inconmensurable.

Para Mary Richmond, quedarse sólo en los diagnósticos en el plano manifiesto de la conducta (de desatención, negligencia hacia los hijos, etcétera) genera situaciones de dependencia y cronicidad. En el interesante análisis de la familia Jones, Mary Richmond describe con enorme inteligencia lo que posteriormente se denominará familias multiproblemáticas o multiservicios. (Minuchin et al., 1967; Malagoli y Rochietta, 1987; Cancrini, 1999). Y cómo las acciones de los profesionales, que sustituyen funciones que deberían ser llevadas a cabo por la familia, no contribuyen al bienestar de las mismas. Más al contrario, lo que manifiesta Richmond en Caso Social individual (1982) es que «lo que nosotros hacemos para nosotros mismos contribuye mucho más a nuestro bienestar permanente que lo que hacen los demás por nosotros». Porque, además, señala, en línea con investigaciones actuales sobre las familias multiproblemáticas, que

Cuando los clientes de los trabajadores sociales (...) son demasiado accesibles a los visitantes es una dificultad. Numerosas personas van y vienen alrededor de ellos, cumpliendo una u otra misión social y cada una de ellas influye en un cierto grado de vida en la familia en su conjunto, aunque esta influencia sea ejercida a menudo de manera completamente inconsciente (p. 120).

La familia y la red social son los ejes fundamentales para la construcción de la identidad del sujeto, y la identidad se construye en la interacción; de ahí que no exista en el ser humano una identidad única, inalterable, más bien hay un sí mismo con límites imprecisos y diferentes contenidos, que se va «a poner en marcha» dependiendo del contexto con el que esté interactuando. En esta línea, Richmond plantea que para comprender las dificultades (comprender al otro) hay que tener una comprensión clara de la actitud de los amigos, del ámbito laboral y observar el feed back entre las partes. Destaca la importancia del trabajo de intervención con la red primaria e institucional, si bien, nos advierte que hay que ir a esta última cuando están agotados los recursos personales del sujeto o familia,

Una vez que todos los planes de tratamiento han fracasado, ya es demasiado tarde para encontrarse con las únicas personas que pueden rellenar los vacíos de la historia pasada (2005, p. 126).

Para que el diagnóstico sea realmente social, al entrevistar a nuestro cliente debemos considerar todas sus facetas de forma global (...) tener presentes tanto la serie de sucesos acaecidos en su vida como sus relaciones sociales. ¿Cuál ha sido la principal tendencia de dichos sucesos? ¿Qué personas o instituciones sociales han ejercido una mayor influencia sobre él? (p. 401).

Además, el trabajo con la red necesita, para la autora: «tiempo y habilidad», ya que posee una permanencia y una significación social que justifica plenamente el esfuerzo cumplido.

Por un lado, individualizada que se desliza bastantes veces hacia la culpabilización de la víctima y la falta de reflexión sobre la relaciones que se establecen entre los sujetos y su entorno; $y$, por el otro, la postura que pone el énfasis en el cambio social, abogando por políticas emancipadoras. Sin embargo, señalábamos también, que no fue éste el conocimiento que trató de transmitirnos Mary Richmond. Aun cuando no puede decirse que la autora participó activamente en ningún campo del trabajo social llevando a cabo reformas sociales, como bien conocemos de Jane Addams, hemos visto que la reforma social se encuentra entre lo que ella denomina una de «las ramas del servicio social». En este punto en concreto de su doctrina, la autora nos remite a la concepción del «ensemble» o conjunto, que 
para los filósofos del pragmatismo americano constituía la dicotomía individuo/sociedad; $\mathrm{y}$, en coherencia con este concepto, la preocupación que estos filósofos tenían por la reforma de las instituciones, puesto que para ellos, «la indivisible experiencia de cambio personal y social en el proceso crítico de reconstrucción recíproca de la organización social» constituía una importancia central (Zamani1lo, 1991, p. 37). De alguna manera se podría conjeturar hoy que lo que hizo Jane Addams en la práctica fue recogido por Mary Richmond en la formalización de un cuerpo doctrinal que hoy puede llegar a tener categoría de teoría si seguimos profundizando en su pensamiento. Eso es lo que hemos intentado en este trabajo. Pues bien, estas ramas agrupadas en: servicios sociales colectivos, reforma social y legislación social, se hallan

En relación recíproca con el servicio social de casos individuales (...). El servicio social de casos individuales se ocupa de establecer mejores relaciones sociales, tratando los individuos uno por uno en el círculo íntimo de la familia, pero el servicio social alcanza también los mismos fines generales por otros medios. Engloba una variedad considerable de operaciones que se ocupan de grupos -centros sociales, obras de recreo, círculos, obras de barrio, obras locales- operaciones en las cuales el individuo, aunque se dirijan directamente a él, no es más que una unidad en un conjunto (...), el servicio de reformas sociales tiende a elevar «en conjunto» las condiciones en las cuales viven las masas, principalmente por la propaganda social y por la legislación social (...). En fin el servicio de investigaciones sociales (...) tiene también como tarea accesoria, la de reunir los hechos conocidos y reinterpretarlo para uso del servicio de reformas sociales, de los servicios sociales colectivos y del servicio social de casos individuales (op. cit.,1982, pp. 48-149).

Para Mary Richmond estas tareas tienen una importancia extraordinaria puesto que contribuyen al progreso social y al desarrollo de la democracia, bien por la vía de la presión y expresión políticas, como se hizo en España en la etapa primera del socialismo, proceso liderado por Patrocinio de las Heras y Elvira Cortajerena que dio origen a las leyes de Servicios Sociales, bien por el papel de defensa de leyes concretas como en el caso siguiente que narra la autora. Se trataba de las resistencias que ponían «los padres y numerosos patronos» a observar la ley de nuevas medidas con respecto al trabajo de menores:

Sé por experiencia personal, hasta qué punto, en cierto Estado, en que en ese momento la industrias tenía más necesidad del trabajo de menores que en cualquier otra parte, la nueva ley hubiera sido letra muerta, sin los esfuerzos abnegados de las obras que se consagran al servicio social de casos individuales (...). Mis colegas, las asistentes sociales, tuvieron que soportar por esta buena causa más vejaciones que antes o después de esta época, pero cuando empezaron a elaborar un plan razonable y adecuado en cada caso en el que se afirmaba que la ley perjudicaba a los padres (...), ellas pudieron, en colaboración con la asociación local para el progreso de la enseñanza pública, hacer que las excepciones a la ley fueran inútiles $o$ inexcusables (p. 155).

La influencia recíproca de diferentes ramas del servicio social merecería ser estudiada más completamente de lo que yo he podido hacerlo, pero parece evidente que todas las ramas se mezclan entre sí en el gran movimiento que lleva al progreso social (p. 161).

Un tema político de total actualidad, que se adentra profundamente en el corazón de la profesión, es el de la defensa de los Servicios Sociales públicos. También se hizo eco de este grave problema en nuestras sociedades de hoy, con el ascenso salvaje del neoliberalismo:

Una parte importante de este conjunto está constituida por el papel que puede desempeñar el servicio social en el terreno de la administración pública (...) en cada una de las ramas del servicio social hay que considerar como uno de sus fines principales el esfuerzo de la acción de servicios públicos (p. 164).

Pero remarca con rotunda afirmación que es necesario que los poderes públicos den garantía de continuidad en su servicio:

Para que los trabajadores sociales especializados en el servicio de casos individuales entren de buena gana y en gran número en el servicio de los poderes públicos, es necesario que éstos den alguna seguridad de continuidad en los métodos seguidos y cierta garantía de independencia ante los partidos políticos (p. 166). 
Nos referíamos al comienzo de este apartado a la necesidad de aumentar la formación para seguir los pasos que se iniciaron con Mary Richmond; queremos ahondar ahora en ello porque ésta, la formación ininterrumpida, constituye un aspecto ético de primer orden para mejorar el ejercicio profesional. Aun cuando en sus obras no se menciona directamente el concepto de ética, el contenido de su programa representa todo un proyecto ético-político. Ético-político en el sentido que da Foucault al compromiso de todo ciudadano en el cuidado de la polis: se trata de acercarse a los problemas políticos en términos de «verdad/poder», tarea y compromiso del «intelectual específico», de aquél que lucha con una conciencia concreta, e inmediata, en los lugares donde le sitúan su trabajo, o sus condiciones de vida (Zamanillo, 2008, p. 75). La dimensión que da Mary Richmond a la acción del Trabajo Social, tal y como hemos visto en este artículo, hace que podamos relacionar, integrar y comprender todo su proyecto en estas palabras de Foucault, así como en el significado que da Paul Ricoeur a la ética: «tender a la vida buena, con y para los otros en instituciones justas». El vivir bien para Ricoeur es hablar de «cuidado». Se trata de aprender a cuidarse uno a sí mismo, aprender de la misma forma a cuidar a los otros y a las instituciones (2005, p. 242). En Mary Richmond, la reconstrucción del individuo y la reforma de las instituciones, mediante la reforma social, evocan este proyecto ético de los dos filósofos citados así como el de los de la escuela del pragmatismo americana. No hay ética sin proyección política $\mathrm{Y}$ en este punto queremos subrayar las palabras de Foucault:

La necesidad del cuidado de uno mismo, la necesidad de ocuparse de uno mismo, está ligada al ejercicio del poder. Ocuparse de uno mismo es algo que viene exigido y a la vez se deduce de la voluntad de ejercer un poder político sobre los otros. No se puede gobernar a los demás, no se pueden transformar los propios privilegios en acción política sobre los otros, en acción racional, si uno no se ha ocupado de sí mismo (1994, p. 42).

La cuestión sobre el poder está en el centro mismo de este proyecto ético ${ }^{6}$.

¿Y qué relación tiene la ética con la formación continua? se preguntarán todavía a estas alturas. Es la mirada ideológica y, por tanto, la elección de la teoría que nos va a dar cuenta y poder analizar las condiciones del «habitar» de las personas, la que nos va a conducir a observar con más amplitud la complejidad del campo de intervención. Y es con Eliana C. Korin con quien vamos a tratar de dar respuesta a esta cuestión. En un magnífico artículo titulado «Desigualdades sociales y relaciones terapéuticas: aplicación de las ideas de Freire a la práctica clínica», la autora narra sus dilemas en la relación terapéutica, debidos, fundamentalmente, a las contradicciones que se generan en el curso de la intervención. La observación constante de Korin de las relaciones que se establecían con las personas que atendía, le llevó a redefinir el problema de la siguiente forma: se trataba, no de problemas irresolubles del tratamiento, sino de un fenómeno social que se mostraba como una «condición de paciente crónico». Existía una pauta de conducta en la relación terapéutica que se manifestaba en una dependencia del consultante hacia el consultor y que, como experiencia común, se extendía a todos aquellos que están sometidos a un ciclo permanente de opresión. Las mujeres que vivían en un aislamiento derivado de la migración y de la fragmentación de sus lazos familiares, así como de los sistemas naturales de apoyo, se volvían cada vez más vulnerables a la dependencia del sistema de atención de la salud como fuente constante de apoyo. La asimetría en la relación con el terapeuta hacía que éste se convirtiera también en agente opresor si se tiene en cuenta que las diferencias que existen entre ambos son abismales en cuanto a la cultura, la raza, la clase social, etcétera. La reflexión sobre todos estos aspectos que dificultaban el vínculo terapéutico llevó a esta profesional a intentar abordar las contradicciones con el método de Freire fundamentado en la

6 Para reflexionar sobre la cuestión del poder en trabajo social véase: Pelegrí, X. El poder en el trabajo social: una aproximación desde Foucault. Cuadernos de Trabajo Social, 17, 45-62; así como en: Zamanillo, T. (2008). Trabajo social con grupos y pedagogía ciudadana. Madrid: Ed. Síntesis. 
«educación para la conciencia crítica». «Este método examina el carácter opresivo de las relaciones no recíprocas», de tal forma que los elementos de análisis con los que se puede analizar la relación entre el terapeuta y el consultante y su familia ayudan a aquél a contar con todos los miembros que componen el nuevo sistema en un proceso de diálogo, de reflexión conjunta y de acción.

En esta reflexión se plantean los problemas derivados de la asimetría de poder partiendo de la siguiente hipótesis que orientó el eje de las conversaciones: "cuanto más éxito tenía en ayudarlas a que se sintieran mejor, más dependientes se volvían de mi ayuda permanente». Por supuesto que la reflexión sobre los preconceptos de la terapeuta era una tarea constante en la redefinición de los problemas que concurrían en la relación (Korin, 1997, pp. 9-14). En apartados anteriores hemos visto el concepto de coparticipación del mismo modo que lo contempla la misma Mary Richmond. A pesar de que ella cuando escribió, no definiera la fuente de sus reflexiones como ideológica y/o teórica, nosotras aquí sí lo hacemos por ser el propósito de este artículo: iluminarlo a la luz de nuevos desarrollos.

¿Y, por tanto, cuál es el conocimiento ético que podemos extraer de la síntesis del artículo de Korin? Son muchos los argumentos que podríamos elegir para sostener una respuesta afirmativa, pero de todos vamos a elegir el que acabamos de señalar en este apartado. Es el concepto de ética de Ricoeur: tender a la vida buena, con y para los otros en instituciones justas. Recordemos también que para seguir un proceso que tienda a la vida buena, lo esencial es ser consciente del cuidado como eje de la relación interpersonal.
La lectura del artículo de Korin nos hará comprender que todos los esfuerzos de esta terapeuta se orientaron a lograr tanto el cuidado de sí misma como profesional -en cuanto al esfuerzo por resolver las contradicciones que surgían en el curso de la intervención psicosocial-, como el cuidado de los otros y de la institución en la que trabajaba, con el fin de lograr unas relaciones más equitativas y justas. Podemos ver también en el artículo citado cómo la autora ha sabido aunar el mundo interno y el mundo externo; cómo ha atendido al individuo, a su medio, y a la relación que se ha establecido entre consultante y terapeuta; cómo ha analizado los hechos desde una perspectiva subjetiva y objetiva; y cómo se ha enfrentado a sus limitaciones y a sus prenociones. En fin, este aprendizaje se extrae también de los ejemplos que pone Mary Richmond en los tres primeros capítulos al examinar la práctica del trabajo social con casos y reflexionar sobre conceptos como «simpatía imaginativa; franqueza y transparencia en la relación; explicación del por qué de sus decisiones, diagnóstico compartido», etcétera.

En resumen, pensamos que la atención a todas estas dimensiones de la realidad social es un requerimiento de la profesión para comprender un mundo cada vez más complejo; es prácticamente una obligación de los docentes que se ha de tener en cuenta desde el inicio de la formación en las escuelas. Y si después de la formación no se ha tenido acceso a este tipo de conocimiento, como muchas veces ocurre, los profesionales no pueden seguir ajenos hoy a la información y conocimiento de los nuevos hallazgos en la investigación que se está desarrollando en los campos «pantanosos» de la intervención psicosocial.

\section{Referencias bibliográficas}

Anderson, H. y Goolishian, H. (1996). Conversación, lenguaje y posibilidades, un enfoque posmoderno de la terapia. Buenos Aires: Amorrortu

Aponte, H. (1985). La persona del terapeuta: piedra angular de la terapia. Sistemas familiares, 1. Auerswald, E. H. (1995). Un trabajo en red poco razonable. Sistemas Familiares, 2.

Boszormenyi-Nagy I. y Framo, J.L (1976). Terapia familiar intensiva. México: Trillas.

Bourdieu, P. (2007). El sentido práctico. Buenos Aires: Siglo XIX.

Bowen, M. (1991). De la familia al individuo. Barcelona: Paidós.

Cancrini, L. (1991). La psicoterapia: gramática y sintaxis. Barcelona: Paidós.

Cancrini, L. (1999). Las familias multiproblemáticas. en L. Coletti y J. L. Linares (comp), Intervención sistémica con familias multiproblemáticas en Servicios Sociales», Barcelona: Paidós. 
Cirillo (1991). Niños maltratados. Barcelona: Paidós.

Fernández, J. M. (2004). Interdisciplinariedad en ciencias sociales: perspectivas abiertas por la obra de Pierre Bourdieu. Cuadernos de Trabajo Social 17, 169-193.

Foucault, M. (1994). Hermenéutica del sujeto. Madrid: La Piqueta.

Framo, J. L. (1996). Familia de origen y psicoterapia. Barcelona: Paidós

Hoffman, L. (1996). Una postura reflexiva para la terapia familiar. En Sh. McNamee y K. J. Gergen, La terapia como construcción social. Barcelona: Paidós.

Hoffman, L. (2001). De la sabiduría sistémica a la responsabilidad relacional: Una perspectiva comunal. Sistemas Familiares, 2.

Korin, E. (1997). Desigualdades sociales y relacionales terapéuticas: aplicación de las ideas de Freire a la práctica clínica. Sistemas familiares, 1, 32-52.

Malagoli Togliati, M. y Rochietta, L. (1987). Famiglie multiproblematiche. Roma: Italia Scientifica.

Minuchin, P. Colapinto, J. y Minuchin, S. (2000). Pobreza, institución, familia, Buenos Aires: Amorrortu.

Minuchin, S. (1977). Familias y terapia familiar. Barcelona: Gedisa

Minuchin, S. y Fichman H. (1984). Técnicas de terapia familiar. Barcelona: Paidós.

Mouro, H. y Simoes, D. (2001). A cien años de la primera escuela de trabajo social. Coimbra: Cuarteto.

Olvera Serrano, M. (2007). Espacio, modernidad, individualización: el legado simmeliano. En Georg Simmel. Una revisión contemporánea. Coordinado por Olga Salido Ramos. Barcelona: Ed. Antrhopos.

Peregrí, X. (2004). El poder en el trabajo social: una aproximación desde Foucault. Cuadernos de Trabajo Social, 17, 21-43.

Pakman, M. (1999). El diseño de terapias constructivas en salud mental comunitaria. Poética y micropolítica en el consultorio y fuera de él. Sistemas Familiares, 2.

Pakman, M. (2006). Reducción del riesgo en familias multiproblemáticas: la macropolítica de la justicia social en la asistencia en salud mental. III Congreso de transtornos del comportamiento en la familia y en la escuela. http://www.obelen.es/biblioteca.php

Ricoeur, P. (2002). Ética y moral. En Carlos Gómez, Doce textos fundamentales de la Ética en el siglo XX. Madrid: Alianza Editorial.

Richmond, M. (1982). Caso social individual. Buenos Aires: Humanitas.

Richmond, M. (2005). Diagnóstico social. Madrid: Siglo XXI

Rodríguez, A. y Zamanillo, T. (1992). Apuntes para una valoración diagnóstica. Treball Social, 127, 48-54.

Rodríguez Rodríguez, A. (2006). Proyecto Docente. Pruebas de Habilitación Nacional Profesor Titular de Escuela Universitaria. Inédita. Madrid.

Selvini, M. (comp.) (1990). Crónica de una investigación. Barcelona: Paidós

Schön, D. (1998). El profesional reflexivo. Barcelona: Paidós.

Sluzki, S. (2007). Interfaces toward a new generation of systemic models in family research and practice. Family Process, 2.

Stierlin, H. (1997). El individuo en el sistema. Psicoterapia en una sociedad cambiante. Barcelona: Herder.

Vidal, F. (2010). Fundamentos de exclusión social y empoderamiento. Madrid: Cáritas Española

Watzlawick, P. (1983). Teoría de la comunicación humana. Barcelona: Herder.

White, M. y Epston, D. (1993). Medios narrativos para fines terapéuticos. Barcelona: Paidós.

Zazzo, R. (1977). La vinculación, una nueva teoría sobre el origen de la afectividad. VV.AA. La vinculación. Alcoy: Marfil.

Zamanillo, T. y Gaitán, L. (1991). Para comprender el trabajo social. Estella: Ed. Verbo Divino.

Zamanillo, T. (2008). Trabajo social con grupos y pedagogía ciudadana. Madrid: Ed. Síntesis. 